\title{
Studying of Modification in Fluence \\ on the Structure and Properties \\ of Deformable Aluminum Alloys of Al-Mg-Si System
}

\author{
Mihail M. Antonov*a, d, \\ Nina V. Okladnikovab ${ }^{b}$,Jury A. Gorbunov ${ }^{c}$, \\ Vladimir P. Zhereb ${ }^{d}$, Tatyana N. Drozdova ${ }^{d}$, \\ Tamara A. Orelkina ${ }^{d}$ and Margarita G. Shamsutdinovad \\ ${ }^{a}$ Ltd. "FMP "SKAD" \\ 1b/1 Zavodskaya Str., Divnogorsk, 660121, Russia \\ ${ }^{b}$ Ltd. "FPP "SEGAL" \\ 103 Pogranichnikov, bld. 4, Krasnoyarsk, 660111, Russia \\ 'LLC "Research \& Development Center "SIAL" \\ 15a Pogranichnikov, bld. 1, Krasnoyarsk, 660111, Russia \\ ${ }^{d}$ Siberian Federal University \\ 79 Svobodny, Krasnoyarsk, 660041, Russia
}

In the article was been investigated the structure and phase composition of the following modifying agents: a rod-shaped ligature AlTi5C0,2 and AlTi5B1, and a dispersed powder mixture MS-M. The influence of modifying agents on the semi-finished product structure and properties from the alloy AD31 were studied. Here was shown that applying the powder mixture for modification ingots from the alloy $A B E$ leaded to the effective grain refining. To apply the $M C-M$ in the serial manufacture of ingots from the alloys of Al-Mg-Si system, is necessary to optimize the composition of modifying agent and its input parameters.

Keywords: modification, the alloys of Al-Mg-Si system, ligature, ingots, sections.

DOI: 10.17516/1999-494X-2015-8-5-601-608.

(C) Siberian Federal University. All rights reserved

* Corresponding author E-mail address: emaciate@mail.ru 


\title{
Влияние модифицирования на структуру \\ и свойства деформируемых сплавов \\ системы Al-Mg-Si
}

\author{
М.М. Антонов ${ }^{\mathrm{a}, \mathrm{r}}$, Н.В. Окладникова ${ }^{\tilde{}}$, \\ Ю.А. Горбунов ${ }^{\text {в }, ~ В . П . ~ Ж е р е б ~}{ }^{\mathrm{r}}$, \\ Т.Н. Дроздова ${ }^{\ulcorner}$Т.А. Орелкинаг, М.Г. Шамсутдинова \\ ${ }^{a} O O O \ll Л M 3 ~ « С К А Д »$ \\ Россия, 660121, Дивногорск, Заводская, 1б/1 \\ ${ }^{\sigma} \mathrm{OOО}$ «ЛПЗ «СЕГАЛ» \\ Россия, 660121, Красноярск, Пограничников, 103 стр. 4 \\ ${ }^{в} О О О$ «Инженерно-технологический центр «СИАЛ» \\ Россия, 660111, Красноярск, Пограничников, 15a, стр. 1 \\ ${ }^{\mathrm{r}}$ Сибирский федеральный университет \\ Россия, 660041, Красноярск, Свободный, 79
}

Исследована структура и фазовый состав модификаторов: лигатурных прутков AlTi5C0,2 и AlTi5B1 и дисперсной порошковой смеси МС-М. Изучено влияние исследуемых модификаторов на структуру слитков и свойства полуфабрикатов из сплавов системы Al-Mg-Si. Показано, что применение порошковой смеси при модифицировании слитков сплава АВЕ привело к существенному измельчению зерна. Для использования $M C-M$ в серийном производстве слитков из сплавов системы $\mathrm{Al}-\mathrm{Mg}$-Si необходимо оптимизировать состав и параметры ввода модификатора.

Ключевые слова: модифицирование, сплавы системы Al-Mg-Si, лигатура, слитки, профили.

\section{Введение}

В настоящее время на рынке прессованной продукции пользуются спросом профили из малолегированных алюминиевых сплавов системы Al-Mg-Si с высоким качеством поверхности под анодирование. Качество поверхности изделий и их свойства существенно зависят от макро-, микроструктуры и морфологии избыточных фаз слитков.

Эффективное воздействие на структуру и качество слитков, связанное с измельчением литого зерна, достигается за счет операции модифицирования. Структурные изменения при этом наследуются на всех этапах технологического производства деформированных полуфабрикатов и влияют на качество поверхности и механические свойства получаемых изделий. При этом поиск новых составов модификаторов и способ их введения в расплав - актуальная задача материаловедения и литейного производства.

Для модифицирования слитков деформируемых алюминиевых сплавов, в том числе сплавов системы Al-Mg-Si, традиционно используется лигатура $\mathrm{Al}-\mathrm{Ti}-\mathrm{B}$, содержащая частицы фаз $\mathrm{TiAl}_{3}$ и $\mathrm{TiB}_{2}$, являющиеся эффективными центрами кристаллизации $[1,2]$.

Известны экспериментальные данные по измельчению зерна слитков алюминиевых сплавов лигатурным прутком Al-Ti-C [3, 4]. Модифицирующий эффект ее обусловлен большим 
структурным сходством карбидов в виде фаз $\mathrm{Al}_{4} \mathrm{C}_{3}$ и $\mathrm{TiC}$ или $\mathrm{Al}_{3} \mathrm{Ti}$ и $\mathrm{TiC}$ с алюминием, что создает благоприятные условия для пристройки к ним атомов алюминия и приводит к измельчению зерна слитка.

В последние годы, помимо модифицирующих лигатурных прутков, широкое распространение получает способ введения в расплав алюминия и его сплавов дисперсных порошков (или нанопорошков), представленных соединениями тугоплавких металлов в виде карбидов, нитридов, оксидов [3, 4].

Главной характеристикой нанопорошков выступает развитая поверхность частиц. Благодаря малым размерам частиц нанопорошков ( $\leq 100$ нм) и их высокой реакционной способности они являются эффективными центрами кристаллизации и, следовательно, измельчают зерно литого сплава.

Целью данной работы стало исследование влияния модифицирования лигатурными прутками и порошковой смесью на структуру слитков и свойства прессованных профилей из сплавов системы Al-Mg-Si.

\section{Исследование структуры лигатурных прутков AITi5B1, AITi5C0,2 и ультрадисперсного порошка МС-М}

Объектами исследования были модификаторы: лигатурные прутки AlTi5B1 и AlTi5C0,2, a также ультрадисперсный порошок МC-Mㄹ.

Микроструктура лигатурного прутка AlTi5B1 (рис. 1а) представляет собой алюминиевый твердый раствор и интерметаллидные частицы: кристаллы фазы $\mathrm{Al}_{3} \mathrm{Ti}$, имеющие форму крупных, неправильных многогранников, расположенные равномерно по сечению прутка, и частицы $\mathrm{TiB}_{2}$ - более мелкие многогранники в виде скоплений небольшой протяжённости.

Количественный анализ структурных составляющих лигатур проводили на оптическом микроскопе Carl Zeiss с использованием программы Axiovision Rel. 4.5. Параметры фаз исследуемых лигатур приведены в табл. 1.

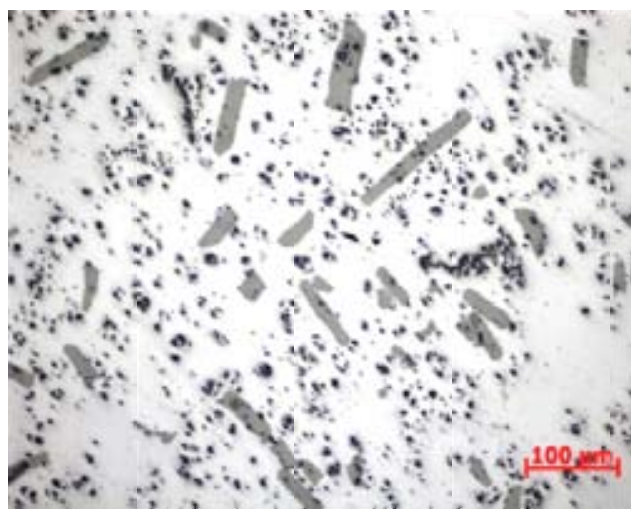

a

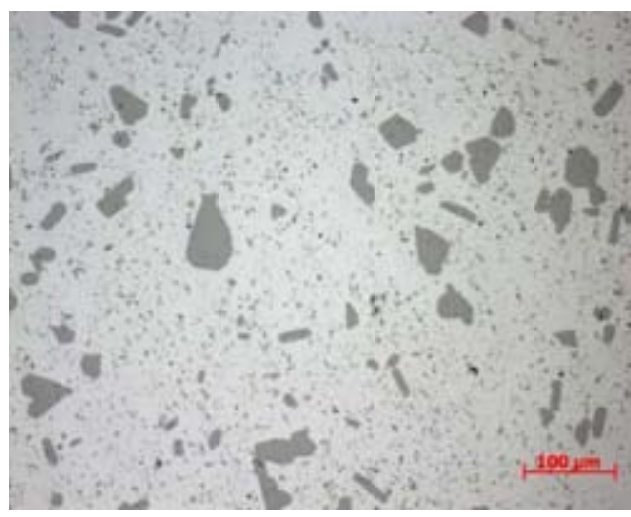

6

Рис. 1. Микроструктура лигатурного прутка в продольном сечении: а - AlTi5B1; б - AlTi5C0,2

Смесь МС-М предоставлена М.Ю. Новомейским.

$$
-603-
$$


Анализ микроструктуры лигатурного прутка AlTi5C0,2 (рис. 1б) показал наличие крупных частиц в форме многогранников, являющихся интерметаллидами $\mathrm{Al}_{3} \mathrm{Ti}$, и мелких частиц в виде строчечных скоплений небольшой протяжённости, которые - предположительно - фаза карбида титана. Количественная обработка микроструктуры (табл. 1) показала, что в отличие от лигатуры AlTi5B1 частицы интерметаллида $\mathrm{Al}_{3} \mathrm{Ti}$ крупнее, но в объеме их распределено меньше.

Для анализа ультрадисперсной модифицирующей смеси МС-М был проведен рентгенофазовый анализ порошка и определен фракционный состав. Ультрадисперсный порошок МC-M содержит оксиды $\mathrm{Ti}, \mathrm{Zr}, \mathrm{Nb}$ и такие соли, как хиолит $\mathrm{Na}_{5} \mathrm{Al}_{3} \mathrm{~F}_{14}$, криолит $\mathrm{Na}_{3} \mathrm{AlF}_{6}$, фторцирконат калия $\mathrm{K}_{2} \mathrm{Zr}_{2} \mathrm{~F}_{6}$, которые участвуют в реакциях восстановления металлов и действуют как рафинирующие добавки к расплаву.

Форму и размеры частиц смеси МС-М определяли на растровом электронном микроскопе EVO50, микрорентгеноспектральный анализ частиц модифицирующей смеси проводили с использованием энергодисперсионного анализатора INCO ENERGY 250. Выявлено, что смесь МC-М представляет собой совокупность частиц, неоднородных по размерам. В порошковой смеси дисперсные частицы оксидов тугоплавких компонентов располагаются на поверхности кристаллов солей, поэлементный состав смеси дан в таблице (рис. 2). Оценка фракционного состава показала, что размер всех частиц порошковой смеси изменяется от 0,1 до 170 мкм. При этом размер частиц оксидов тугоплавких металлов, входящих в конгломераты, находится в пределах 0,1-2 мкм.

Таблица 1. Размеры интерметаллидных частиц и их объемная доля

\begin{tabular}{|l|c|c|c|c|c|}
\hline Лигатура & Фаза & $\begin{array}{c}\text { Объемная доля } \\
\text { частиц, \% }\end{array}$ & $\begin{array}{c}\text { Средний размер } \\
\text { частиц, мкм }\end{array}$ & $\begin{array}{c}\text { Максимальный } \\
\text { размер частиц, } \\
\text { мкм }\end{array}$ & $\begin{array}{c}\text { Минимальный } \\
\text { размер частиц, } \\
\text { мкм }\end{array}$ \\
\hline \multirow{2}{*}{ AlTi5B1 } & $\mathrm{Al}_{3} \mathrm{Ti}$ & $11,9 \pm 2$ & $37,6 \pm 3$ & 49,1 & 26,1 \\
\cline { 2 - 6 } & $\mathrm{TiB}_{2}$ & $14,4 \pm 3$ & $0,95 \pm 0,02$ & 0,42 & 2,20 \\
\hline AlTi5C0,2 & $\mathrm{Al}_{3} \mathrm{Ti}$ & $7,4 \pm 3$ & $40,8 \pm 3$ & 51,6 & 30,1 \\
\hline
\end{tabular}

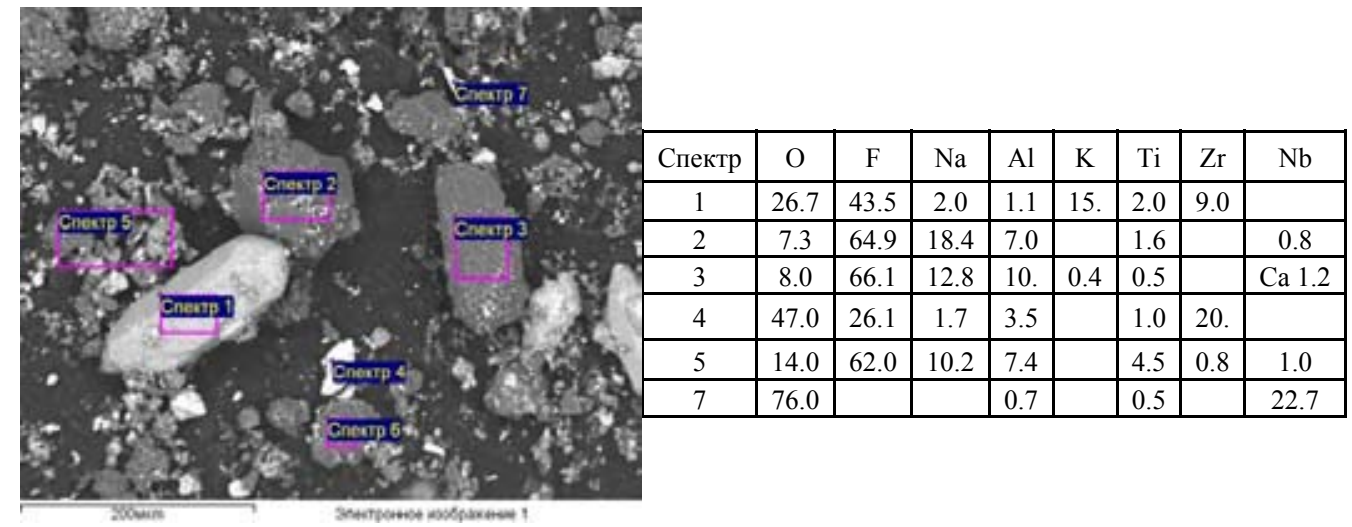

Рис. 2. Микроструктура смеси МС-М (РЭМ) и поэлементный состав частиц смеси (вес. \%)

$$
-604-
$$




\section{Влияние лигатурных прутков AITi5B1 и AITi5C0,2 и порошковой смеси МС-М на литую структуру слитков и свойства профилей из сплавов системы Al-Mg-Si}

Объектом исследования служили слитки из сплава АД31 диаметром 145 мм, полученные на производстве и модифицированные с помощью лигатурного прутка AlTi5B1 и AlTi5C0,2 с расходом 0,6 кг/т расплава².

Для выявления зерен в литых слитках проводили оксидирование образцов и изучали их в поляризованном свете. Из анализа микроструктуры (рис. 3) следует, что размер зерна слитков, модифицированных лигатурой AlTi5C0,2, примерно на 40 \% больше, чем размер зерна в слитках, модифицированных AlTi5B1. К тому же в слитках, модифицированных AlTi5C0,2, на периферийной части наблюдаются участки с веерной дефектной структурой.

Размер дендритной ячейки - важнейший параметр литой микроструктуры, который зависит, прежде всего, от условий охлаждения слитка. Поэтому влияние модификаторов, ввод которых не связан с изменением технологии литья, не должен оказывать существенного влияния на ее размер. Следовательно, размер дендритной ячейки в слитках, изготовленных с использованием лигатурных прутков AlTi5B1 и AlTi5C0,2, практически одинаков и составляет 30 мкм в средней и 45 мкм в периферийной части слитков.

Известно, что значительный модифицирующий эффект оказывает введение в расплав дисперсных порошков, содержащих частицы химических соединений тугоплавких элементов на основе боридов, нитридов, оксидов [3, 4]. Для изучения воздействия порошкового модификатора на микроструктуру сплавов были выполнены исследования в лабораторных условиях на сплаве АBE.

Объектом исследования являлись технологические пробы (Alcan тест) из сплава ABE.

Анализ макроструктуры проб показал, что размер зерна в пробе, модифицированной порошковой смесью МC-М, значительно меньше, чем в пробе, модифицированной AlTi5B1 (рис. 4). Полученный результат модифицирования слитка смесью МС-М можно объяснить тем,

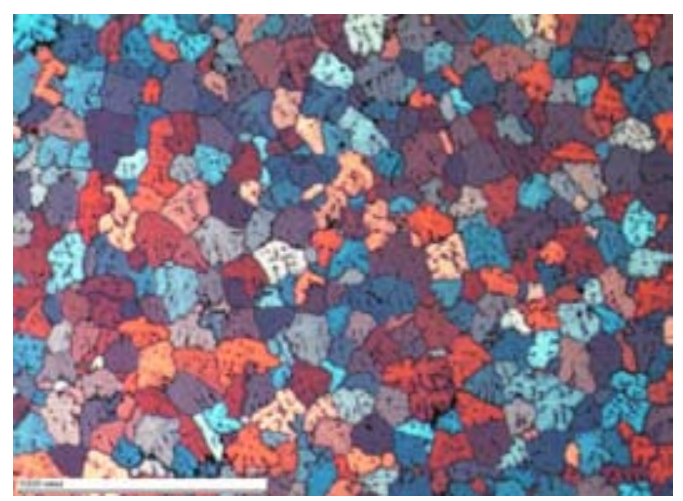

a

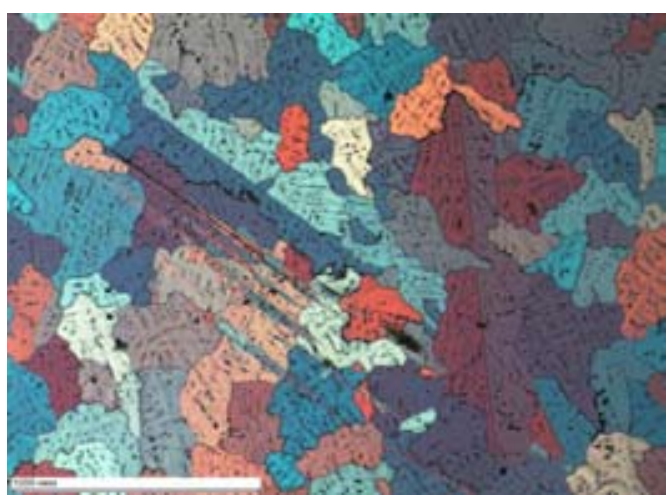

6

Рис. 3. Микроструктура образцов слитков из АД31, модифицированных лигатурой: а - AlTi5B1; б-AlTi5C 0,2

2 Слитки получены при участии М.С. Фроленкова, Л.П. Трифоненкова.

$$
-605-
$$




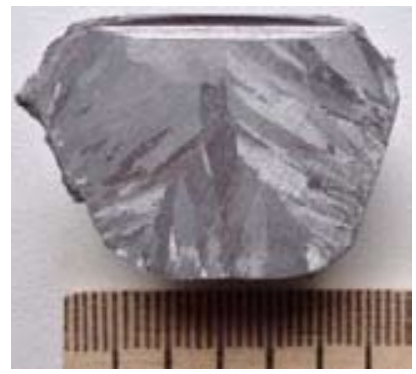

$\mathrm{a}$

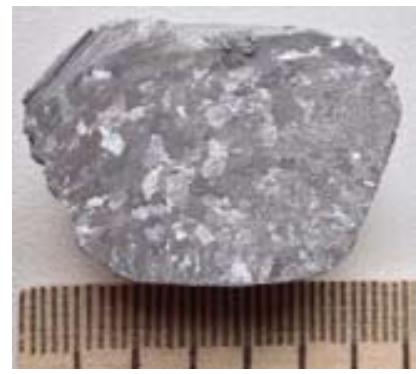

6

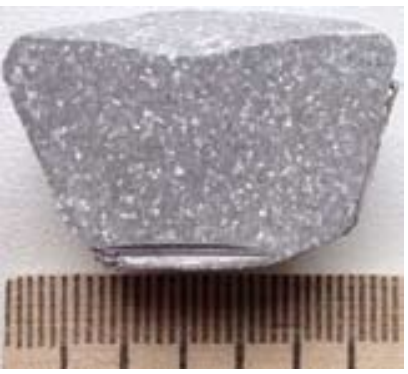

B

Рис. 4. Макроструктура алкан-теста проб сплава ABE: а - без модифицирования; б - модифицированного AlTi5B1; в - модифицированного МС-М

что частицы оксидов тугоплавких металлов $\mathrm{Ti}, \mathrm{Zr}, \mathrm{Nb}$ имеют размеры доли микрон. Вероятные химические реакции восстановления металлов из оксидов, осуществляемые в расплаве, предполагают образование в итоге интерметаллидов $\mathrm{Al}_{3} \mathrm{Ti}, \mathrm{Al}_{3} \mathrm{Zr}$ и $\mathrm{Al}_{3} \mathrm{Nb}$, которые выступают центрами кристаллизации. Учитывая имеющиеся литературные данные, можно предположить, что размер интерметаллидов тугоплавких металлов, полученных в ходе реакций восстановления оксидов смеси МС-М, составляет от десятков до сотен нанометров. Как следствие, эффект модифицирования порошковой смесью оказывается заметно выше в сравнении с прутковой лигатурой, где готовые центры кристаллизации $\mathrm{Al}_{3} \mathrm{Ti}$ и $\mathrm{TiB}_{2}$ имеют ощутимо большие размеры.

Для подтверждения модифицирующего эффекта порошковой смеси МС-М на производстве была проведена плавка слитков из сплава АД31 диаметром 145 мм. Также были отлиты слитки с использованием лигатурного прутка AlTi5B1. Исследовано влияние вышеприведенных модификаторов на литую макро- и микроструктуру сплава АД31. Анализ макроструктуры слитков показал, что в слитках, модифицированных МС-М, не достигнуто однородности структуры, наблюдаются участки с крупным зерном в литниковой части. В донной части макроструктура по сечению слитка равномерная. Таким образом, однородности макроструктуры слитка при модифицировании порошковой смесью МС-М не достигнуто.

Размер зерна в середине слитка, модифицированного МС-М, примерно на 60 \% больше размера зерна слитка, модифицированного лигатурой AlTi5B1 (рис. 5). В опытных слитках выявлены крупные зерна, главным образом в периферийной части. Помимо этого в микроструктуре определяются участки мелких кристаллов, соизмеримые с размером дендритных ячеек, которые распределены неоднородно по сечению слитка (рис. 62). Эти участки свидетельствуют о локальном, эффективном модифицировании опытных слитков порошковой MC-M. В слитках, модифицированных лигатурой AlTi5B1, сформирована однородная по сечению структура.

Можно предположить, что неравномерность зерна опытных слитков связана с недостаточной интенсивностью перемешивания расплава, в том числе и за счет барботации при проведении плавки в печи большого объема, и - как следствие - с неравномерным распределением частиц модификаторов. При проведении дальнейших работ в промышленных масштабах это требует решения вопроса (например, с использованием МГД-перемешивателей) и, вероятно, увеличения продолжительности выдержки расплава после введения порошковой смеси.

$$
-606-
$$




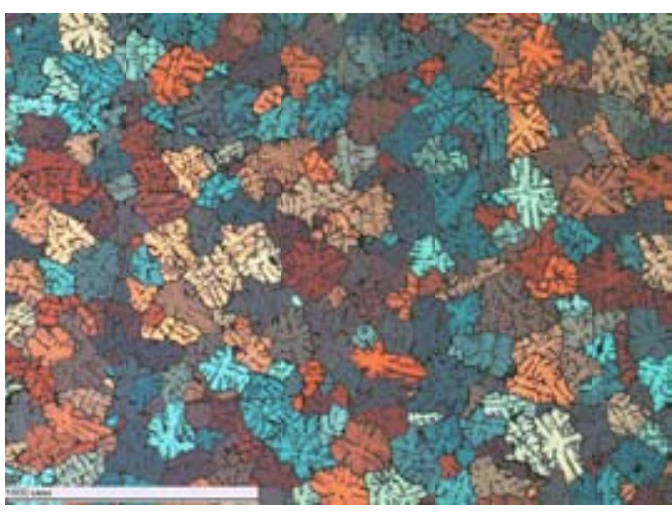

a

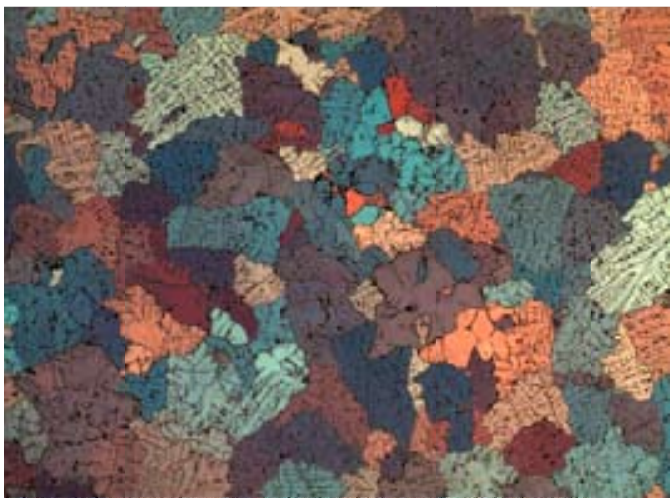

B

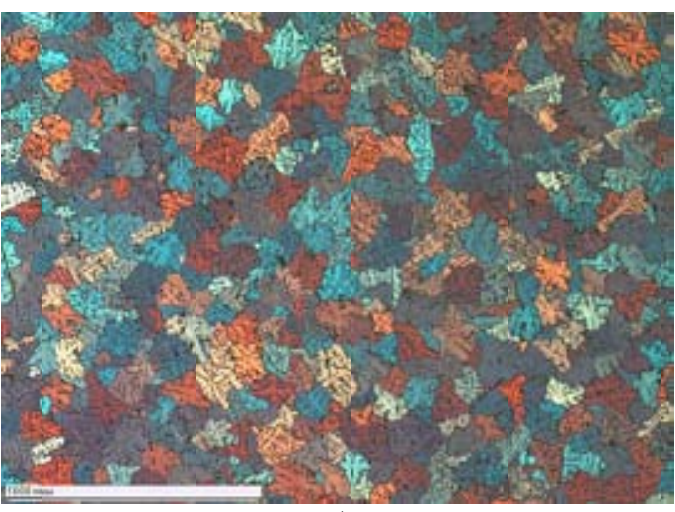

6

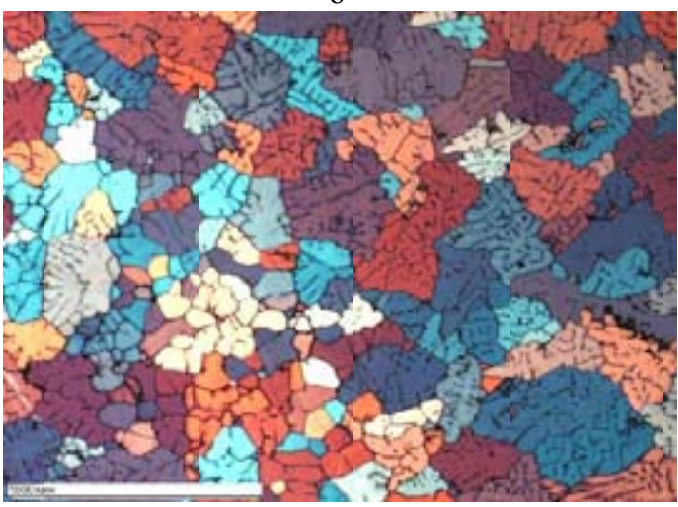

$\Gamma$

Рис. 5. Микроструктура образцов слитков из АД31, модифицированных лигатурой: а, б - AlTi5B1; в, г-МС-М; а, в - средняя часть слитка; б, г - периферийная часть слитка

В литом состоянии микроструктура слитков неравновесная и содержит по границам ячеек твердого раствора эвтектические фазы $\mathrm{Mg}_{2} \mathrm{Si}, \alpha\left(\mathrm{Al}_{8} \mathrm{Fe}_{2} \mathrm{Si}\right), \beta\left(\mathrm{Al}_{5} \mathrm{FeSi}\right)$. На производстве для слитков проводят гомогенизационный отжиг, основными задачами которого являются гомогенизация твердого раствора, а также трансформация частиц фазы $\beta-\mathrm{Al}_{5} \mathrm{FeSi}$ и сфероидизация железистых фаз [5, 6].

Для оптимизации параметров гомогенизационного отжига в лабораторных условиях отжиг опытного сплава (модифицированного МС-М) проводили при температуре 580, 590, 600, $610,620^{\circ} \mathrm{C}$ и времени выдержки 10-180 мин. По микроструктуре осуществляли количественный анализ железистых фаз образцов в литом и отожженном состоянии. Основным параметром обработки структуры в программе AxioVixion был выбран показатель сферичности частиц железосодержащих фаз.

Из литературных данных известно, что высокотемпературные нагревы способствуют реализации процессов трансформации, фрагментации, сфероидезации железосодержащих фаз и чем выше температура отжига, тем интенсивнее происходят эти процессы, даже при малых выдержках $[5,6]$. По результатам исследований, проведенных в работе, также подтверждена эффективность высокотемпературного кратковременного отжига и рекомендовано использовать для слитков отжиг по режиму $600{ }^{\circ} \mathrm{C}, 30$ мин по сравнению с отжигом по серийному режиму $580^{\circ} \mathrm{C}, 3$ ч. 
Для оценки влияния параметров прессования на качество и механические свойства профилей из опытных слитков сплава АД31, модифицированных смесью МС-М, прессование проводили при температурах 460, 480 и $500{ }^{\circ} \mathrm{C}$ и коэффициентах вытяжки 78 и 66. Механические свойства профилей были определены после упрочняющей термообработки (старение при 180-190 ㄷ, 5 ч). Было показано, что температура прессования не оказывает значительного влияния на уровень прочностных свойств и шероховатость поверхности профилей. Механические свойства профилей, полученных из слитков, модифицированных МС-М, выше требований ГОСТ 22233.

\section{Выводы}

1. Установлено, что модифицирование прутковой лигатурой AlTi5C0,2 слитков диаметром 145 мм из сплава АД31 приводит к получению неудовлетворительной разнозернистой и веерной структуры.

2. Выявлено, что применение порошковой смеси при модифицировании привело к существенному измельчению зерна лабораторных слитков сплава АВЕ. Для использования МС-М в серийном производстве слитков из АД31 необходимо оптимизировать состав и параметры ввода модификатора.

3. Показано, что для образцов слитков из опытного сплава, модифицированного МС-М, отжиг при высокой температуре $600-620^{\circ} \mathrm{C}$ с кратковременной выдержкой в течение 30 мин является более эффективным по сравнению с серийным режимом.

4. Уровень механических свойств и качества поверхности профилей из слитков опытной плавки сплава АД31 соответствует уровню профилей, полученных по серийной технологии, и удовлетворяет заданным значениям по ГОСТ 22233.

\section{Список литературы}

[1] Белов Н.А. Фазовый состав промышленных и перспективных алюминиевых сплавов. М.: МИСиС, 2010. $511 \mathrm{c.}$

[2] Макаров Г.С. Слитки из алюминиевых сплавов с магнием и кремнием для прессования: основы производства. М.: Интермет Инжиниринг, 2011. 256 с.

[3] LI Jian-guo et. al. // Nonferrous Met. Soc. China. 2006. N 16. P. 243-253.

[4] Попова Э.А. и др. // Металлы. 2009. № 5. С. 3-9.

[3] Крушенко Г.Г. // Металлургия машиностроения. 2011. № 1. С. 20-24.

[4] Крушенко Г.Г. // Нанотехника. 2008. № 2. С. 18-21

[5] Бряниев П.Ю. Автореф. дис. ... канд. техн. наук. М., 2007. 25 с.

[6] Брянцев П. Б. // Металловедение и термическая обработка металлов. 2012. № 6. C. $24-27$. 